\title{
Impact of primary health care on mortality from heart and cerebrovascular diseases in Brazil: a nationwide analysis of longitudinal data
}

\author{
OPEN ACCESS
}

\author{
Davide Rasella postdoctoral researcher ${ }^{1}$, Michael O Harhay PhD student ${ }^{3}$, Marina L Pamponet \\ researcher ${ }^{1}$, Rosana Aquino associate professor ${ }^{12}$, Mauricio L Barreto professor ${ }^{12}$
}

${ }^{1}$ Instituto de Saúde Coletiva, Federal University of Bahia, Rua Basílio da Gama, s/n, Salvador, Bahia, Brazil; ${ }^{2}$ Ciência, Tecnologia e Inovação em Saúde, INCT-CITECS, Salvador, Bahia, Brazil; ${ }^{3}$ Center for Clinical Epidemiology and Biostatistics, University of Pennsylvania School of Medicine, Philadelphia, USA

\begin{abstract}
Objectives To evaluate the impact of Brazil's recently implemented Family Health Program (FHP), the largest primary health care programme in the world, on heart and cerebrovascular disease mortality across Brazil from 2000 to 2009

Design Ecological longitudinal design, evaluating the impact of FHP using negative binomial regression models for panel data with fixed effects specifications.
\end{abstract}

Setting Nationwide analysis of data from Brazilian municipalities covering the period from 2000 to 2009 .

Data sources 1622 Brazilian municipalities with vital statistics of adequate quality.

Main outcome measures The annual FHP coverage and the average FHP coverage in previous years were used as main independent variables and classified as none $(0 \%)$, incipient $(<30 \%)$, intermediate $(30-69 \%)$, or consolidated ( $\geq 70 \%)$. Age standardised mortality rates from causes in the group of cerebrovascular (ICD-10 codes 160-69), ischaemic (ICD-10 I20-25), and other forms of heart diseases (ICD-10 I30-52), which were included in the national list of ambulatory care-sensitive conditions, were calculated for each municipality for each year. They accounted for $40 \%$ of all deaths from these groups during the study period.

Results FHP coverage was negatively associated with mortality rates from cerebrovascular and heart diseases (ambulatory care-sensitive conditions) in both unadjusted and adjusted models for demographic, social, and economic confounders. The FHP had no effect on the mortality rate for accidents, used as a control. The rate ratio for the effect of consolidated annual FHP coverage on cerebrovascular disease mortality and on heart disease mortality was 0.82 (95\% confidence interval 0.79 to 0.86 ) and 0.79 ( 0.75 to 0.80$)$ respectively, reaching the value of 0.69 ( 0.66 to 0.73 ) and 0.64 (0.59 to 0.68 ) when the coverage was consolidated during all the previous eight years. Moreover, FHP coverage increased the number of health education activities, domiciliary visits, and medical consultations and reduced hospitalisation rates for cerebrovascular and heart disease. Several complementary analyses showed quantitatively similar results.

Conclusions Comprehensive and community based primary health care programmes, such as the FHP in Brazil, acting through cardiovascular disease prevention, care, and follow-up can contribute to decreased cardiovascular disease morbidity and mortality in a developing country such as Brazil.

\section{Introduction}

Cardiovascular disease is the leading cause of mortality among non-communicable chronic diseases and is responsible for $30 \%$ of all global deaths, constituting a large and growing burden in middle and low income countries. ${ }^{1-3}$ Ischaemic heart disease and cerebrovascular disease are responsible for the majority of cardiovascular disease mortality, accounting for 7.6 million and 5.7 million of deaths annually, respectively, ${ }^{4}$ and are leading causes of disease burden as measured in disability adjusted life years lost. ${ }^{56}$

The control, management, and prevention of cardiovascular disease and other non-communicable diseases is fundamentally different from acute care, relying on several features for success typically found within a strong primary health care system, and an approach centred primary health care could represent a cost effective strategy to reduce the cardiovascular disease burden in low and middle income countries. ${ }^{78}$

In Brazil, the Ministry of Health has designated the Family Health Program (FHP), the main primary health care programme of the country, as the leading initiative in the national strategy 
for reduction of cardiovascular disease and other diseases. ${ }^{9} 10$ The FHP was launched in 1994 and has experienced a dramatic expansion within and across Brazil's 5564 municipalities. Presently, FHP, has become the world's largest community based primary health care programme, present in $95 \%$ of municipalities and covering $53 \%$ of the Brazilian population in 2011. ${ }^{11}$

The major expansion of primary health care in Brazil through the FHP has translated into improved population health outcomes, ${ }^{12}{ }^{13}$ and FHP activities include health promotion, primary prevention and management of cardiovascular disease risk factors, as well as secondary prevention for high risk individuals (monitoring of hypertension and diabetes) and rehabilitation of patients with cardiovascular disease, orchestrated primarily through domiciliary visits and community interventions operated by community health workers. ${ }^{10}{ }^{14}$ In 2009, a list of ambulatory care-sensitive conditions was created to monitor primary health care performance and evaluate its cost effectiveness. ${ }^{15}$ In the past decade in the country a decline of about $20 \%$ in the age standardised mortality rates for ischaemic heart and cerebrovascular diseases has been documented-reaching 69.2 and 70.7 deaths per 100000 inhabitants respectively in 2009. ${ }^{16}{ }^{17}$ However, the mechanisms causing this decline have not been examined or identified, and it is speculated to be consequence (among others) of successful implementation of health policies that led to the expansion of access to primary health care. ${ }^{18}$ Ambulatory care-sensitive conditions represented $40 \%$ of the mortality from cerebrovascular and ischaemic and other forms of heart disease, accounting for more than half a million deaths in the past decade. ${ }^{11}$

The aim of the present study is to evaluate the impact of the FHP on age standardised mortality rates from heart and cerebrovascular diseases included in the ambulatory care-sensitive conditions, as well as the impact on some potential intermediate mechanisms, such as health promotion activities and hospitalisations for cardiovascular disease, in the period 2000 to 2009 in Brazilian municipalities.

\section{Methods}

This study employs a mixed ecological design by combining an ecological multiple-group and longitudinal time-trend design..$^{19}$ The unit of analysis is the municipality (county) Descriptive analyses of the trend of hospitalisation and mortality rates for the selected cardiovascular disease causes and for all the variables along the period under study were performed; subsequently regression models to assess the association between FHP coverage and cardiovascular disease were fitted; and finally several complementary analyses, including difference-in-difference and propensity score matching, were performed to verify the robustness of the results.

From the 5507 Brazilian municipalities in 2000, we selected those that had adequate vital information according to criteria based on five indicators ${ }^{20}$ : (1) age standardised mortality rate; (2) ratio of reported live births to estimated live births; (3) average annual deviation from the three year period mean of the mortality rate; (4) average annual deviation from the three year period mean of the birth rate; and (5) proportion of ill defined deaths (ICD-10 (international classification of diseases, 10th revision) codes R95-R99). For the period under study, 1622 municipalities met the inclusion criteria for adequacy of vital information, representing $30 \%$ of the municipalities in Brazil. (Figure 1S in the supplementary data on bmj.com shows the distribution of the selected municipalities in the country.)
We calculated age standardised mortality rates for ages 20-74 years by cause of death for each municipality by the method of direct standardisation, using the Brazilian population structure of the year 2000 as the standard population. With the intention of selecting specific causes of cardiovascular disease that could be reduced by the FHP, we considered the Brazilian List of Ambulatory Care Sensitive Hospitalisations (ICSAP), ${ }^{15}$ a set of conditions for which access to effective primary care can decrease the rate of hospitalisation in Brazil. Among the causes of death listed within the ICD-10, we selected the ones from the groups of ischaemic heart diseases and other forms of heart diseases (codes I20 (angina pectoris), I24 (other acute ischaemic heart diseases), I50 (heart failure, including pulmonary oedema J81)) and cerebrovascular diseases (codes I63 (cerebral infarction), I64 (stroke, not specified as haemorrhage or infarction), I65 (occlusion and stenosis of precerebral arteries, not resulting in cerebral infarction), I66 (occlusion and stenosis of cerebral arteries, not resulting in cerebral infarction), I67 (other cerebrovascular diseases), I69 (sequelae of cerebrovascular disease, including transient cerebral ischaemic attacks and vascular syndromes of brain in cerebrovascular diseases G45 and G46)). Mortality from accidents (codes V01-X59) was included as a negative control, because the FHP was not expected to influence this and does not include actions related to accident prevention. Thus, we hypothesised an effect of FHP on mortality associated with cardiovascular disease but not mortality from accidents.

Two different metrics for FHP coverage, our exposure to treatment, were considered: (1) annual FHP coverage, derived by dividing the number of persons in FHP catchment areas by the total population of the municipality; and (2) the average FHP coverage in the previous four, six, and eight years, derived by the sum of the annual coverage of the previous four, six, and eight years divided by the number of respective years. The average FHP coverage measures the effect of duration of FHP implementation and the level of exposure. For example, we hypothesised that the effect of consistent high population coverage for a period of eight consecutive years would yield greater outcomes than high annual coverage only recently attained in the municipality. To aid comparisons and to obtain meaningful risk ratio estimates of the FHP effect, we categorised FHP coverage, both annual and average, using cut-offs used in previous studies: without FHP (0), incipient (coverage of $<30 \%$ of the population), intermediate (coverage $>30 \%$ and $<70 \%$ ), and consolidated (coverage $\geq 70 \%) .{ }^{12} 1321$

Covariates recognised in the literature as determinants of mortality from cardiovascular disease were selected a priori for inclusion in the mathematical models. ${ }^{322} 23$ These covariates were stratified according to the median or, when available, reference values for Brazil. They included percentage of people below the poverty line in the municipality (stratified as $\leq 15.9 \%$ and $>15.9 \%$, median of the distribution), per capita income (monthly, stratified as $\leq \mathrm{R} \$ 525$ and $>\mathrm{R} \$ 525$, median of the distribution), percentage of individuals having basic household appliances (stratified as $\leq 48.8 \%$ and $>48.8 \%$, median of the distribution), percentage of individuals living in households with inadequate sanitation (stratified as $\leq 13.8 \%$ and $>13.8 \%$, median of the distribution), percentage of illiterates individuals over 15 years old (stratified as $\leq 11.0 \%$ and $>11.0 \%$, median of the distribution), presence of local hospital beds, number physicians per 1000 inhabitants (stratified as $\leq 0.55$ and $>0.55$, median of the distribution), urbanisation rate (stratified as $\leq 76.6 \%$ and $>76.6 \%$, median of the distribution), percentage of highly educated (university graduated) among those $>25$ years old (stratified as $\leq 4.8 \%$ and $>4.8 \%$, median of the 
distribution), and presence of tomography and ultrasonography in the municipality.

\section{Data sources}

The data used in this study were collected from different national information systems. We obtained statistics made available by the Brazilian Ministry of Health from the Mortality Information System, Primary Care Information System, and Outpatient Information System. ${ }^{11}$ Socioeconomic and demographic variables were retrieved from the Brazilian Institute of Geography and Statistics. ${ }^{24}$ Because these covariates were obtained from the 2000 and 2010 national censuses databases, the annual values from 2001-09 were calculated by linear interpolation.

\section{Statistical analyses}

We employed multivariable conditional negative binomial regression models for panel data with fixed effects specification. The appendix on bmj.com gives a detailed explanation on the advantages of these models in impact evaluations, which are increasingly used in the recent literature, ${ }^{12} 132125$ together with the regression formula used. Negative binomial regression is used when the outcome to be analysed is a count (such as deaths during a calendar year) and the Poisson model assumption that the mean is equal to variance is not met, usually because the data present greater dispersion. ${ }^{26}$ Longitudinal, also termed panel data, models include a disturbance or error term and a second term to control for unobserved time-invariant characteristics of the unit of analysis. In our analysis, these unobserved time-invariant characteristics would be the unmeasured geographical, historical, or sociocultural characteristics of each municipality. ${ }^{27}$

The choice of fixed effect or random effect models was based on the Hausman specification test and on the fact that fixed effects models permit correlations between the unobserved time-invariant term and the explanatory variables, such as the overall coverage of the programmes, allowing to control for possible selection bias in the implementation of FHP. ${ }^{28}$ As explained in the appendix, in order to verify if conditional models were removing the fixed effects of each panel, ${ }^{26}$ we fit models with different specifications, such as unconditional negative binomial regression models and conditional Poisson regressions with robust standard errors. Conditional, fixed effects, negative binomial regression models seemed to be the most appropriate for our analysis. These regression models were selected to estimate mortality rate ratios, both crude and adjusted, using municipalities with no coverage of FHP as reference category.

To elucidate the mechanism of action of the FHP, we analysed the association of FHP coverage with process variables such as the number of health education activities performed in the community, the number of domiciliary visits or consultations of health professionals of any level over the population of the municipality, and the number of medical consultations in primary care. These activities constitute an important part of the FHP health prevention and promotion strategy. ${ }^{10}$ In order to strengthen the plausibility of an effect of the FHP on cardiovascular disease mortality, multivariate models with the same independent variables were fitted using as outcome hospitalisation rates for the same ICD codes of the mortality under study. A variable representing time was not included in the models because the mortality rate ratio, comparing two groups of coverage exposed to the same mortality time trend, allowed us to control for secular trends. A detailed explanation of the theoretical aspects and sensitivity tests we performed to reasonably exclude the possibility of relevant uncontrolled secular trends is outlined in the appendix.

In order to assess the robustness of the fixed effect, multivariate regression models, we conducted a difference-in-difference analysis using the municipalities with no FHP coverage in 2000 $(n=849)$, the years 2000 and 2009, and the same FHP coverage levels and covariates used in the fixed effects models. As further analysis with the same database, we conducted a propensity score matching analysis and fixed effects, multivariate regressions with propensity score weighting.

For database processing and analysis, Stata software version 12.0 was used.

\section{Results}

In the municipalities examined, the age standardised mortality rate for ambulatory care-sensitive conditions, according to the ICSAP list, decreased $32.7 \%$ in the group of cerebrovascular diseases and $44.6 \%$ in the group of heart diseases (table $1 \Downarrow$ ). From 2000 to 2009, the FHP coverage increased $227 \%$. Socioeconomic conditions improved during the period, with the per capita income increasing $36.5 \%$ and the percentage of individuals living in households with inadequate sanitation decreasing $40.2 \%$.

Table $2 \Downarrow$ shows the crude and adjusted association of mortality from cardiovascular disease with annual FHP coverage levels. After adjustment, the cerebrovascular mortality rate was $14 \%$ lower with intermediate FHP coverage compared with no coverage and $18 \%$ lower with consolidated coverage (both statistically significant). The percentage reduction is obtained by subtracting from $100 \%$ the rate ratio estimated by the statistical model. For heart diseases the reduction was greater, reaching $21 \%$ with consolidated FHP coverage group and maintaining the statistical significance across all levels of FHP coverage. The FHP coverage had no effect on the mortality rate for accidents, used as control.

Table $3 \Downarrow$ presents the impact of average FHP coverage in each municipality over the past four, six, and eight years exhibiting a dose-response decrease in mortality rates with greater average FHP coverage in the previous years. The effect reached a maximum of a $31 \%$ decrease for cerebrovascular diseases and $36 \%$ for ischaemic and other forms of heart disease, and maintained statistical significance across all levels of FHP coverage. The differences between mortality rate ratio estimates for the annual (table $2 \Downarrow$ ) and four, six, and eight year FHP coverage (table $3 \Downarrow$ ) were statistically significant (confidence intervals not overlapping) for most comparisons and model specifications. As with the annual coverage models, the FHP coverage showed no effect on the mortality rate from accidents, regardless the level of coverage of the previous years.

The number of per capita health education activities performed in the community and the number of per capita domiciliary visits of health professionals and of medical consultations in primary care were positively associated with the average FHP coverage of the past eight years (table $4 \Downarrow$ ). The average FHP coverage over the past eight years was associated with a reduction in hospitalisation rates related to heart and cerebrovascular diseases, with a similar magnitude to that found in the mortality rates analysis (table $4[\mathrm{t} 4$ ).

The difference-in-difference analysis using the years 2000 and 2009 , performed to verify the robustness of the fixed effect regression findings, showed a strong and statistically significant 
effect of FHP, following the gradient of increased FHP coverage for both mortality rates (see appendix on bmj.com).

The FHP average treatment effect estimates obtained with the propensity score matching analysis and the FHP rate ratio estimates obtained with the fixed effects negative binomial regression models weighted for the propensity score - performed as further analyses of the robustness of the results-are similar and confirm the findings of the study. The detailed results and explanations of the methodology are available in the appendix.

As a final sensitivity analysis, we fitted our models using data from all Brazilian municipalities, which had on average a lower overall community socioeconomic status than the selected ones, and found similar and statistically significant results, with a mortality rate ratio for the effect of consolidated FHP coverage during the previous eight years of 0.78 (95\% confidence interval 0.75 to 0.81 ) on ischaemic and other forms of heart disease mortality and 0.96 (0.94 to 0.99 ) on cerebrovascular disease mortality (see appendix table $5 \mathrm{~S}$ ).

\section{Discussion}

To our knowledge, this is the first study to analyse the effect of a countrywide primary health care programme on cardiovascular disease mortality. The results of our study show that the Family Health Program (FHP) coverage is associated with a reduction in hospitalisations and mortality from heart and cerebrovascular disease causes - included in the national ambulatory care-sensitive list-in Brazil. Moreover, its effect increases according to the duration of FHP's implementation in the municipality. Diseases in this group of causes are considered preventable or treatable at the primary care level and represent an important share of cardiovascular disease mortality in the country, accounting for $42 \%$ of the cerebrovascular, ischaemic, and other forms of heart diseases mortality in 2000, and decreasing to $37 \%$ in $2009 .{ }^{11}{ }^{15} 16$ The effects we found are plausible because an increase in FHP coverage was also associated with other factors potentially involved in reducing cardiovascular disease mortality. For instance, FHP is positively associated with the number of health education activities, domiciliary visits from health professionals, and medical consultations in primary care, while it was associated with reduced numbers of hospitalisations for cardiovascular diseases. The FHP negative association with hospitalisations for cardiovascular disease shows that the reduction in cardiovascular disease mortality is not due to an increase in cardiovascular disease hospitalisations: the FHP has an effect further upstream in the causal pathways of cardiovascular disease mortality. Other studies have already shown FHP coverage to be associated with reductions of hospitalisations for overall ambulatory care-sensitive conditions in Brazil in recent years. ${ }^{29}$ Finally, in our models the FHP has no significant associations with mortality from accidents, used here as control because FHP does not perform activities for its prevention. This strengthens the plausibility that the associations we identified between cardiovascular disease and FHP coverage are not artefacts of residual confounding.

Our findings are supported by recent studies using individual level data. A cohort study in Brazil identified a strong reduction of recurrent cardiovascular episodes in patients after they had their first stroke or myocardial infarction episode if they were receiving FHP secondary prevention activities. ${ }^{30}$ Furthermore, studies in Denmark and England have demonstrated both reduction in mortality and increase in life expectancy associated with preventive health screening and consultation at the primary care level. ${ }^{31} 32$
Primary health care can reduce cardiovascular disease morbidity and mortality through primary prevention of risk factors, secondary prevention of complications resulting from existing risk factors, and rehabilitation and prevention of future complications. ${ }^{33}$ The greater proximity of primary health care facilities to patients' homes and the fact that primary health care is usually free of charge (as in Brazil) or requires only low fees can reduce geographical and economic barriers to access and make primary prevention, care, and patient follow-up easier. ${ }^{8}$ For these reasons, primary health care is considered an extremely cost effective strategy to deal with cardiovascular disease, particularly in developing countries. ${ }^{34}$ To this end, the FHP in Brazil is playing an important role in the national policy for the comprehensive care of non-communicable diseases and is implementing a special programme, "Hiperdia," for care and follow-up of diabetes and hypertension, including the free access to drugs for these diseases. ${ }^{35}$ FHP could reduce cardiovascular disease through health promotion and prevention activities, as shown by the FHP's effect of increase of educational activities in the community, and through a better monitoring and follow-up at the curative level, as shown by the higher number of domiciliary visits and medical consultations in areas covered by FHP. Previous studies have shown the increase of health promotion and prevention activities by FHP and its association with mortality reduction in children, ${ }^{12}{ }^{13}$ and shown that the implementation of the FHP in rural areas has increased population access to healthcare. ${ }^{21}$

As in any fixed effects regression model on panel data, the longitudinal dimension of the data is used to estimate the associations between dependent and independent variables. ${ }^{27}$ In particular, our findings show an increasing FHP effect when we consider the average coverage of the programme in the previous four, six, and eight years, demonstrating the importance of the duration of implementation of the programme on its impact on this group of non-communicable diseases. This is expected because interventions to reduce risk of cardiovascular disease could require a certain time lag before having a full effect. ${ }^{36}$ However, our study also shows that the annual FHP coverage has a strong impact, suggesting a short term effect as well. This is confirmed by previous studies that show that substantial reductions in cardiovascular disease mortality can and do occur within months of the implementation of public health interventions. ${ }^{37} 38$

\section{Strengths and limitations of study}

One of the limitations of our analysis is the possibility of ecological fallacy: associations measured at an ecological level do not necessarily reflect associations at the individual level. ${ }^{19}$ Even if our inference level is ecological (that is, we want to determine the effectiveness of an health policy at an aggregate level), the plausibility of our ecological associations rely in part on individual level associations: the increasing survival of individuals due to FHP healthcare. Specifically, in our study it is impossible to determine with certainty if the individuals who experienced the outcome, in this case death from cardiovascular disease, were under FHP coverage, because the only information available is at the aggregate level of municipalities. However, it has to be considered that in the municipality FHP is implemented with greatest priority in deprived neighbourhoods, where avoidable mortality for cardiovascular disease (due to poor socioeconomic conditions and geographical, economic, and cultural barriers to healthcare) is higher than in the rest of the municipality. ${ }^{39}{ }^{40}$ In this case the reduction of these avoidable deaths, controlling for all confounding factors and selection bias, is plausibly and partly due to the inclusion of these 
vulnerable individuals in a FHP catchment area. ${ }^{25}$ It has also to be considered that the use of small units of analysis reduce the possibility of ecological fallacy, ${ }^{41}$ and in our study $75 \%$ of the municipalities had less than 25000 inhabitants.

\section{Even if the association between FHP coverage and} cardiovascular disease mortality rates had been adjusted for all major cardiovascular disease determinants, some factors that could have influenced cardiovascular disease mortality, such as specific food manufacture regulations, smoke control policies, or improvements in the cardiovascular disease treatment have not been included in our mathematical models. To our knowledge, during the period under study, the only countrywide policy introduced in Brazil to reduce cardiovascular disease risk factors and not associated with FHP implementation was related with smoking. ${ }^{42}$ If some other regulations were introduced at the local level, the fact that they were no directly associated with the FHP means they should not be considered in the group of potential confounding factors in our models. ${ }^{19}$

While the FHP effect estimates have been adjusted for healthcare related variables - such as the number of physicians, the presence of hospital beds, availability of computed tomography and ultrasonography in the municipality-it has not been possible to include a variable related to the introduction of new cardiovascular disease treatments. In such a case, the variable would not be associated with the FHP expansion but instead with general ambulatory services and hospital coverage, and it should not be considered a confounding factor in our models. The associations we found between cardiovascular disease mortality and the number of physicians, hospital beds, and presence of computed tomography and magnetic resonance imaging confirm the relevance, besides the primary health care, of the higher levels of care in Brazil. ${ }^{18}$

Even if we have not included some determinant of cardiovascular disease mortality in our models, because of the lack of information at the municipal level, our overall strategy of analysis, which included the use of mortality from accidents as a control for the specificity of FHP effects, ${ }^{43}$ the detection of an effect gradient according to percentage and duration of FHP coverage, and the evaluation of FHP effects in relevant process indicators and hospitalisation rates could reasonably rule out any possible residual confounding in our association of interest. A strength of the study is the selection of municipalities with adequate vital information quality, which improved the study's internal validity. ${ }^{20}$ The quality criteria included a reduced percentage of ill defined causes of death (ICD-10 codes R00-R98) among all death of the municipality $(<16-20 \%)$, assuring that deaths from cardiovascular disease registered by error as ill-defined could not affect the estimated impact of FHP. Finally, to verify our external validity, we fitted our models with data from all Brazilian municipalities, which showed similar and significant FHP effects, indicating that our main findings could be generalised for all the country.

\section{Conclusions}

Countries such as Brazil are undergoing profound demographic and epidemiological changes that have engendered a rise in the percentage of deaths due to non-communicable diseases in recent decades. ${ }^{17} 18$ Thus, in most low and middle income countries, cardiovascular disease mortality has become a huge challenge for health systems that still have to deal with a pre-existing burden of infectious diseases, ${ }^{47}$ while in many Latin American countries, even though cardiovascular disease mortality is decreasing, disparities in terms of trends and current rates still remain. ${ }^{44}$ Our study shows that a countrywide strategy of comprehensive primary health care that includes actions of primary and secondary prevention, care, and follow-up of cardiovascular disease is associated with a reduction of morbidity and mortality from cardiovascular disease in a developing country such as Brazil.

We thank Célia Landmann Szwarcwald, professor of the Institute of Communication and Information Science and Technology in Health, Oswaldo Cruz Foundation, Brazil, for having granted access to the list of municipalities with adequate vital information according to her published article criteria. We thank the Instituto de Saúde Coletiva and the Federal University of Bahia for infrastructural support.

Contributors: DR, MOH, RA, and MLB were involved in the study's conception and design. DR and MLP were involved in data acquisition and analysis and, with MLB, data interpretation. DR and $\mathrm{MOH}$ wrote the first draft of the article, and all authors revised it for important intellectual content and approved the final version for publication. DR is the guarantor of the study, and all authors had full access to all of the data in the study and take responsibility for the integrity of the data and the accuracy of the data analysis.

Funding: Financial support the study was provided by the National Council for Scientific and Technological Development (CNPq). The funding was not specific for the study described in this article. The funder had no role in study design, data collection, data analysis, data interpretation, writing of the report, or in the decision to submit this article for publication. All researchers' decision have been entirely independent from funders.

Competing interests: All authors have completed the ICMJE uniform disclosure form at www.icmje.org/coi_disclosure.pdf and declare: no support from any organisation for the submitted work; no financial relationships with any organisations that might have an interest in the submitted work in the previous three years; no other relationships or activities that could appear to have influenced the submitted work.

Ethical approval: Not needed for this study.

Transparency: The lead author affirms that this manuscript is an honest, accurate, and transparent account of the study being reported; that no important aspects of the study have been omitted; and that any discrepancies from the study as planned (and, if relevant, registered) have been explained.

Data sharing: The full dataset and technical appendix are available from the corresponding author.

Kim AS, Johnston SC. Global variation in the relative burden of stroke and ischemic heart disease. Circulation 2011;124:314-23.

2 Gaziano TA. Reducing the growing burden of cardiovascular disease in the developing world. Health Aff 2007;26:13-24.

3 WHO. Preventing chronic diseases a vital investment. WHO, 2008.

4 Lindholm LH, Mendis S. Prevention of cardiovascular disease in developing countries. Lancet 2007;370:720-2.

5 Mathers CD, Loncar D. Projections of global mortality and burden of disease from 2002 to 2030. PLoS Med 2006;3:e442.

6 Samb B, Desai N, Nishtar S, Mendis S, Bekedam H, Wright A, et al. Prevention and management of chronic disease: a litmus test for health-systems strengthening in low-income and middle-income countries. Lancet 2010:376:1785-97.

7 Lim SS, Gaziano TA, Gakidou E, Reddy KS, Farzadfar F, Lozano R, et al. Prevention of cardiovascular disease in high-risk individuals in low-income and middle-income countries: health effects and costs. Lancet 2007;370:2054-62.

8 Beaglehole R, Epping-Jordan J, Patel V, Chopra M, Ebrahim S, Kidd M, et al. Improving the prevention and management of chronic disease in low-income and middle-income countries: a priority for primary health care. Lancet 2008;372:940-9.

9 Ministério da Saúde. [Guidelines and recommendations for an continuous care of Non-transmissible chronic diseases: promotion, surveillance, prevention and assistance ] [in Portuguese]. Ministério da Saúde, 2008.

10 Ministério da Saúde, Departamento de Atenção Básica. [Practical guidelines of the Family Health Program ] [in Portuguese]. Ministério da Saúde, 2001.

11 Ministério da Saúde. Departamento de Informática do SUS. DATASUS . www2.datasus. gov.br/datasus/index.php.

12 Rasella D, Aquino R, Barreto ML. Reducing childhood mortality from diarrhea and lower respiratory tract infections in Brazil. Pediatrics . 2010;126:e534-40.

13 Aquino R, de Oliveira NF, Barreto ML. Impact of the family health program on infant mortality in Brazilian municipalities. Am J Public Health . 2009;99:87-93.

14 Ribeiro AG, Cotta RM, Ribeiro SM. [The promotion of health and integrated prevention of risk factors for cardiovascular diseases] [in Portuguese]. Cien Saude Colet 2012;17:7-17.

15 Alfradique ME, Bonolo PD, Dourado I, Lima-Costa MF, Macinko J, Mendonca CS, et al. [Ambulatory care sensitive hospitalizations: elaboration of Brazilian list as a tool for 


\section{What is already known on this topic}

Primary health care programmes have been advanced as a cost effective strategy to confront the growing burden of cardiovascular disease occurring in low- and middle income countries

However, there are no longitudinal studies on the effectiveness of nationwide primary health care programs on morbidity and mortality from cardiovascular disease in this setting

\section{What this study adds}

This assessment of primary health care effectiveness in Brazil, a middle income country that has the world's largest primary health care programme, suggests that a nationwide strategy of comprehensive primary health care can substantially reduce morbidity and mortality from heart and cerebrovascular diseases in developing countries

measuring health system performance (Project ICSAP—Brazil)] [in Portuguese]. Cadernos de Saude Publica 2009;25:1337-49.

16 De Fatima Marinho de Souza M, Gawryszewski VP, Orduñez P, Sanhueza A, Espina MA. Cardiovascular disease mortality in the Americas: current trends and disparities. Heart 2012;98:1207-12.

17 Ministério da Saúde. Saúde Brasil 2010 [Health Brazil 2010] [in Portuguese]. Ministério da Saúde, 2011

18 Schmidt MI, Duncan BB, Silva GAE, Menezes AM, Monteiro CA, Barreto SM, et al. Health in Brazil 4 Chronic non-communicable diseases in Brazil: burden and current challenges. Lancet 2011;377:1949-61.

19 Rothman KJ, Greenland S, Lash TL. Modern epidemiology . Lippincott Williams \& Wilkins, 2008.

20 De Andrade CLT, Szwarcwald CL. [Socio-spatial inequalities in the adequacy of Ministry of Health data on births and deaths at the municipal level in Brazil, 2000-2002] [in Portuguese]. Cad Saude Publica 2007-23:1207-16.

21 Rasella D, Aquino R, Barreto ML. Impact of the Family Health Program on the quality of vital information and reduction of child unattended deaths in Brazil: an ecological longitudinal study. BMC Public Health 2010;10:380.

22 Winkleby MA, Jatulis DE, Frank E, Fortmann SP. Socioeconomic-status and health-how education, income, and occupation contribute to risk-factors for cardiovascular-disease. Am J Public Health 1992;82:816-20.

23 Steptoe A, Shamaei-Tousi A, Gylfe A, Henderson B, Bergstrom S, Marmot M. Socioeconomic status, pathogen burden and cardiovascular disease risk. Heart 2007;93:1567-70.

24 IBGE. [Results of the national census 2010] [in Portuguese]. www.censo2010.ibge.gov. $\mathrm{br} /$.

25 Rasella D, Aquino R, Santos CA, Paes-Sousa R, Barreto ML. Effect of a conditional cash transfer programme on childhood mortality: a nationwide analysis of Brazilian municipalities. Lancet 2013;382:57-64.

26 Hilbe JM. Negative binomial regression. Cambridge University Press, 2007.

27 Wooldridge JM. Introductory econometrics, a modern approach . 3rd ed. South-Western College, 2005.

28 Shahidur RK. Koolwal GB, Samad HA. Handbook on impact evaluation: quantitative methods and practices. World Bank Publications, 2010.

29 Macinko J, Dourado I, Aquino R, Bonolo Pde F, Lima-Costa MF, Medina MG, et al. Major expansion of primary care in Brazil linked to decline in unnecessary hospitalization. Health Aff (Millwood) 2010;29:2149-60.

30 Cabral NL, Franco S, Longo A, Moro C, Buss TA, Collares D, et al. The Brazilian Family Health Program and secondary stroke and myocardial infarction prevention: a 6-year cohort study. Am J Public Health 2012;102:e90-5.

31 Rasmussen SR, Thomsen JL, Kilsmark J, Hvenegaard A, Engberg M, Lauritzen T, et al Preventive health screenings and health consultations in primary care increase life expectancy without increasing costs. Scand J Public Health 2007;35:365-72.
32 Levene LS, Baker R, Bankart MJG, Khunti K. Association of features of primary health care with coronary heart disease mortality. JAMA 2010;304:2028-34.

33 Macinko J, Dourado I, Guanais FC. Chronic diseases, primary care and health systems performance diagnostics, tools and interventions. Inter-American Development Bank discussion paper. IDB-DP-189, 2011

34 Miranda JJ, Kinra S, Casas JP, Smith GD, Ebrahim S. Non-communicable diseases in low- and middle-income countries: context, determinants and health policy. Trop Med Int Health 2008:13:1225-32.

35 Ministério da Saúde. [Hiperdia Programme] [in Portuguese] http://portal.saude.gov.br/ portal/se/datasus/area.cfm?id_area $=807$.

36 Law M, Wald N. Why heart disease mortality is low in France: the time lag explanation. BMJ 1999;318:1471-80.

37 Capewell S, O'Flaherty M. Rapid mortality falls after risk-factor changes in populations. Lancet 2011;378:752-3.

38 Capewell S, O'Flaherty M. Can dietary changes rapidly decrease cardiovascular mortality rates? Eur Heart J 2011;32:1187-9.

39 Reddy KS. Cardiovascular disease in non-Western countries. N Engl J Med 2004;350:2438-40

40 Ishitani LH, Franco GD, Perpetuo IH, Franca E. Socioeconomic inequalities and premature mortality due to cardiovascular diseases in Brazil. Rev Saude Publica 2006;40:684-91.

41 Wakefield J. Ecologic studies revisited. Annu Rev Public Health 2008:29:75-90.

42 Levy D, de Almeida LM, Szklo A. The Brazil Sim Smoke policy simulation model: the effect of strong tobacco control policies on smoking prevalence and smoking-attributable deaths in a middle income nation. PLoS Med 2012;9:e1001336.

43 Craig P, Cooper C, Gunnell D, Haw S, Lawson K, Macintyre S, et al. Using natural experiments to evaluate population health interventions: new MRC guidance. J Epidemio/ Community Health 2012;66:1182-6.

44 De Fatima Marinho de Souza M, Gawryszewski VP, Orduñez P, Sanhueza A, Espinal MA. Cardiovascular disease mortality in the Americas: current trends and disparities. Heart 2012;98:1207-12.

Accepted: 02 June 2014

Cite this as: BMJ 2014;348:g4014

This is an Open Access article distributed in accordance with the Creative Commons Attribution Non Commercial (CC BY-NC 3.0) license, which permits others to distribute, remix, adapt, build upon this work non-commercially, and license their derivative works on different terms, provided the original work is properly cited and the use is non-commercial. See: http://creativecommons.org/licenses/by-nc/3.0/. 


\section{Tables}

Table 1/ Standardised mortality rates (SMR) and variables of 1622 selected municipalities in Brazil, 2000-09

\begin{tabular}{|c|c|c|c|c|}
\hline & \multicolumn{2}{|c|}{ Year } & \multirow[b]{2}{*}{ Difference } & \multirow[b]{2}{*}{$\%$ change } \\
\hline & 2000 & 2009 & & \\
\hline \multicolumn{5}{|l|}{ Mean (SD) standardised mortality rates*: } \\
\hline Cerebrovascular diseases $\dagger$ & $40.1(27.7)$ & $27.0(19.8)$ & -13.1 & -32.7 \\
\hline Heart diseases $†$ & $23.3(21.8)$ & $12.9(13.3)$ & -10.4 & -44.6 \\
\hline Accidents & $41.8(29.8)$ & $47.0(32.0)$ & +5.2 & +12.4 \\
\hline Mean (SD) coverage of Family Health Program (\%) & $21.0(30.8)$ & $68.6(33.5)$ & +47.6 & +227 \\
\hline Mean (SD) monthly per capita income $(\mathrm{R} \$)$ & $452.8(163.7)$ & $617.9(191.6)$ & +165.1 & +36.5 \\
\hline Mean (SD) percentage of population below poverty line & $26.1(15.4)$ & $12.9(10.6)$ & -13.2 & -51.1 \\
\hline Mean (SD) percentage of population having basic household appliances & $41.4(15.8)$ & $59.3(21.0)$ & +17.9 & +43.2 \\
\hline Mean (SD) percentage of population in households with inadequate sanitation & $21.6(16.7)$ & $12.9(11.4)$ & -8.7 & -40.2 \\
\hline Mean (SD) percentage illiteracy among people aged $>15$ years & $14.2(7.5)$ & $10.5(6.1)$ & -3.7 & -26.1 \\
\hline Mean (SD) No of hospital beds per 1000 inhabitants & $3.32(3.96)$ & $2.63(2.61)$ & -0.69 & -20.8 \\
\hline Mean (SD) No of physicians per 1000 inhabitants & $0.43(0.60)$ & $0.86(0.66)$ & +0.43 & +100 \\
\hline Mean (SD) urbanisation rate & $70.0(20.1)$ & $74.2(18.6)$ & +4.2 & +6 \\
\hline Mean (SD) percentage highly educated among people aged $>25$ years & $3.6(2.4)$ & $6.8(3.1)$ & +3.2 & +88.8 \\
\hline Percentage of municipalities with computed tomography and ultrasonography & 2.7 & 10.0 & +7.3 & +370 \\
\hline
\end{tabular}

*Rates per 100000 inhabitants aged 20-74 years.

†Causes included in the Brazilian list of ambulatory care-sensitive conditions. 
Table 2| Fixed effect negative binomial models for crude and adjusted association between standardised mortality rates and annual coverage with Family Health Program (FHP) in 1622 selected municipalities in Brazil, 2000-09

\begin{tabular}{|c|c|c|c|c|c|c|}
\hline \multirow[b]{2}{*}{ Variables } & \multicolumn{2}{|c|}{$\begin{array}{c}\text { Cerebrovascular diseases } \\
\text { mortalityrate }\end{array}$} & \multicolumn{2}{|c|}{ Heart diseases mortality rate } & \multicolumn{2}{|c|}{ Accidents mortality rate } \\
\hline & $\begin{array}{l}\text { Crude rate } \\
\text { ratio }(95 \% \mathrm{Cl})\end{array}$ & $\begin{array}{c}\text { Adjusted rate ratio } \\
(95 \% \mathrm{Cl})\end{array}$ & $\begin{array}{l}\text { Crude rate } \\
\text { ratio }(95 \% \mathrm{Cl})\end{array}$ & $\begin{array}{c}\text { Adjusted rate ratio } \\
(95 \% \mathrm{Cl})\end{array}$ & $\begin{array}{l}\text { Crude rate } \\
\text { ratio }(95 \% \mathrm{Cl})\end{array}$ & $\begin{array}{c}\text { Adjusted rate ratio } \\
(95 \% \mathrm{Cl})\end{array}$ \\
\hline \multicolumn{7}{|l|}{ FHP population coverage: } \\
\hline No coverage & 1 & 1 & 1 & 1 & 1 & 1 \\
\hline Incipient (>0 to <30\%) & $\begin{array}{l}0.94 \text { (0.92 to } \\
0.97)\end{array}$ & $0.98(0.95$ to 1.00$)$ & $\begin{array}{l}0.93(0.89 \text { to } \\
0.94)\end{array}$ & 0.98 (0.94 to 1.02$)$ & $\begin{array}{c}1.00(0.97 \text { to } \\
1.02)\end{array}$ & 0.99 (0.96 to 1.02$)$ \\
\hline Intermediate ( $\geq 30 \%$ to $<70 \%$ ) & $\begin{array}{l}0.79 \text { (0.76 to } \\
0.81)\end{array}$ & 0.86 (0.83 to 0.89$)$ & $\begin{array}{l}0.73(0.70 \text { to } \\
0.76)\end{array}$ & 0.81 (0.78 to 0.85$)$ & $\begin{array}{l}0.99 \text { (0.96 to } \\
1.02)\end{array}$ & $0.97(0.95$ to 1.00$)$ \\
\hline Consolidated ( $\geq 70 \%)$ & $\begin{array}{l}0.71 \text { ( } 0.69 \text { to } \\
0.74)\end{array}$ & $0.82(0.79$ to 0.86$)$ & $\begin{array}{l}0.66(0.63 \text { to } \\
0.69)\end{array}$ & $0.79(0.75$ to 0.80$)$ & $\begin{array}{c}1.04(1.01 \text { to } \\
1.08)\end{array}$ & $1.02(0.98$ to 1.06$)$ \\
\hline $\begin{array}{l}\text { Percentage of population below } \\
\text { poverty line }>15.9 \%\end{array}$ & - & $1.10(1.07$ to 1.13$)$ & - & 1.11 (1.06 to 1.15$)$ & - & $1.00(0.97$ to 1.03$)$ \\
\hline $\begin{array}{l}\text { Monthly per capita income } \\
>\mathrm{R} \$ 525\end{array}$ & - & 0.96 (0.93 to 0.99$)$ & - & 0.97 (0.93 to 1.02$)$ & - & $1.02(0.97$ to 1.05$)$ \\
\hline $\begin{array}{l}\text { Percentage of population having } \\
\text { basic household appliances } \\
>48.4 \%\end{array}$ & - & 0.97 (0.94 to 0.99$)$ & - & 0.96 (0.91 to 0.99$)$ & - & $1.04(1.01$ to 1.07$)$ \\
\hline $\begin{array}{l}\text { Percentage of population in } \\
\text { households with inadequate } \\
\text { sanitation }>13.8 \%\end{array}$ & - & 1.07 (1.03 to 1.12$)$ & - & $1.10(1.03$ to 1.17$)$ & - & 0.99 (0.95 to 1.03$)$ \\
\hline $\begin{array}{l}\text { Percentage illiteracy among } \\
\text { people aged over } 15 \text { years } \\
>11.0 \%\end{array}$ & - & 1.08 (1.05 to 1.12$)$ & - & 1.09 (1.04 to 1.15$)$ & - & $1.00(0.96$ to 1.03$)$ \\
\hline Presence of local hospital beds & - & $0.93(0.85$ to 1.02$)$ & - & $0.86(0.75$ to 0.98$)$ & - & $0.95(0.87$ to 1.04$)$ \\
\hline $\begin{array}{l}\text { No of physicians per } 1000 \\
\text { inhabitants }>0.55\end{array}$ & - & 0.97 (0.95 to 0.99$)$ & - & 0.95 (0.92 to 0.98$)$ & - & $1.02(1.00$ to 1.05$)$ \\
\hline Urbanisation rate $>76.6$ & - & 0.93 (0.88 to 0.99$)$ & - & 0.980 .90 to 1.07 ) & - & 0.99 (0.93 to 1.05$)$ \\
\hline $\begin{array}{l}\text { Percentage highly educated } \\
\text { among people aged over } 25 \text { years } \\
>4.8 \%\end{array}$ & - & 0.94 (0.91 to 0.97$)$ & - & 0.89 (0.85 to 0.93$)$ & - & $1.01(0.98$ to 1.04$)$ \\
\hline $\begin{array}{l}\text { Presence of tomography and } \\
\text { ultrasonography in municipality }\end{array}$ & - & $0.86(0.84$ to 0.88$)$ & - & 0.88 (0.85 to 0.91$)$ & - & 0.97 (0.95 to 0.99$)$ \\
\hline No of observations & & 16220 & & 16150 & & 16220 \\
\hline No of municipalities & & 1622 & & 1615 & & 1622 \\
\hline
\end{tabular}


Table 3| Fixed effect negative binomial models for adjusted association ${ }^{*}$ between standardised mortality rates and average coverage of Family Health Program (FHP) in 1622 selected municipalities in Brazil, 2000-09

\begin{tabular}{|c|c|c|c|}
\hline \multirow[b]{2}{*}{ Variables } & \multicolumn{3}{|c|}{ Adjusted rate ratio $(95 \% \mathrm{Cl})$} \\
\hline & $\begin{array}{c}\text { Cerebrovascular diseases mortality } \\
\text { rate }\end{array}$ & Heart diseases mortality rate & Accidents mortality rate \\
\hline \multicolumn{4}{|c|}{$\begin{array}{l}\text { Average FHP population coverage in past } 4 \\
\text { years: }\end{array}$} \\
\hline No coverage & 1 & 1 & 1 \\
\hline Incipient ( $>0$ to $<30 \%$ ) & $0.92(0.89$ to 0.95$)$ & $0.92(0.88$ to 0.96$)$ & 0.99 (0.96 to 1.02$)$ \\
\hline Intermediate $(\geq 30 \%$ to $<70 \%)$ & $0.83(0.80$ to 0.86$)$ & 0.81 (0.78 to 0.85$)$ & 0.99 (0.96 to 1.02$)$ \\
\hline Consolidated $(\geq 70 \%)$ & 0.77 (0.74 to 0.81$)$ & 0.75 (0.71 to 0.79$)$ & $1.02(0.98$ to 1.07$)$ \\
\hline
\end{tabular}

Average FHP population coverage in past 6

years:

\begin{tabular}{llll}
\hline No coverage & 1 & 1 & 1 \\
\hline Incipient $(>0$ to $<30 \%)$ & $0.90(0.87$ to 0.92$)$ & $0.90(0.86$ to 0.94$)$ & $0.99(0.96$ to 1.02$)$ \\
\hline Intermediate $(\geq 30 \%$ to $<70 \%)$ & $0.82(0.79$ to 0.85$)$ & $0.79(0.75$ to 0.82$)$ & $1.00(0.97$ to 1.03$)$ \\
\hline Consolidated $(\geq 70 \%)$ & $0.73(0.70$ to 0.76$)$ & $0.69(0.65$ to 0.73$)$ & $1.03(0.98$ to 1.07$)$ \\
\hline
\end{tabular}

Average FHP population coverage in past 8

years:

\begin{tabular}{lcccc}
\hline No coverage & 1 & 1 & 1 \\
\hline Incipient $(>0$ to $<30 \%)$ & $0.89(0.86$ to 0.92$)$ & $0.89(0.85$ to 0.93$)$ & $1.00(0.97$ to 1.03$)$ \\
\hline Intermediate $(\geq 30 \%$ to $<70 \%)$ & $0.81(0.78$ to 0.84$)$ & $0.78(0.75$ to 0.83$)$ & $1.01(0.97$ to 1.04$)$ \\
\hline Consolidated $(\geq 70 \%)$ & $0.69(0.66$ to 0.73$)$ & $0.64(0.59$ to 0.68$)$ & $1.02(0.98$ to 1.07$)$ \\
\hline No of observations & 16220 & 16150 & 16220 \\
\hline No of municipalities & 1622 & 1615 & 1622 \\
\hline
\end{tabular}

*Models adjusted for percentage of population below poverty line, per capita income (monthly), percentage of population having basic household appliances, percentage in households with inadequate sanitation, percentage illiteracy among $>15$ year olds, presence of local hospital beds, number of physicians per 1000 inhabitants, urbanisation rate, percentage highly educated among $>25$ year olds, and presence of tomography and ultrasonography in the municipality. 
Table 4| Fixed effect negative binomial models for adjusted association ${ }^{\star}$ between process variables, hospitalisation rates, and average coverage of Family Health Program (FHP) in past 8 years in 1622 selected municipalities in Brazil, 2000-07

\begin{tabular}{|c|c|c|c|c|c|}
\hline \multirow[b]{2}{*}{ Variables } & \multicolumn{5}{|c|}{ Adjusted rate ratio $(95 \% \mathrm{Cl})$} \\
\hline & $\begin{array}{l}\text { No of health education } \\
\text { activities performed in the } \\
\text { community over the } \\
\text { population }\end{array}$ & $\begin{array}{c}\text { No of domiciliary visits or } \\
\text { consultations of any health } \\
\text { professionals over the } \\
\text { population }\end{array}$ & $\begin{array}{l}\text { No of medical } \\
\text { consultations in primary } \\
\text { care over the population }\end{array}$ & $\begin{array}{c}\text { Cerebrovascular } \\
\text { diseases } \\
\text { hospitalisation rate† }\end{array}$ & $\begin{array}{c}\text { Heart diseases } \\
\text { hospitalisation rate }\end{array}$ \\
\hline \multicolumn{6}{|l|}{$\begin{array}{l}\text { Average FHP population } \\
\text { coverage in past } 8 \text { years: }\end{array}$} \\
\hline No coverage & 1 & 1 & 1 & 1 & 1 \\
\hline Incipient (>0 to <30\%) & $1.23(1.16$ to 1.31$)$ & 1.53 (1.45 to 1.62$)$ & $1.02(0.99$ to 1.04$)$ & 0.88 (0.85 to 0.90$)$ & 0.89 (0.87 to 0.91$)$ \\
\hline $\begin{array}{l}\text { Intermediate }(\geq 30 \% \text { to } \\
<70 \%)\end{array}$ & 2.13 (2.01 to 2.27 ) & 3.36 (3.18 to 3.55$)$ & 1.11 (1.08 to 1.13$)$ & 0.82 (0.79 to 0.85$)$ & 0.83 (0.80 to 0.85$)$ \\
\hline Consolidated ( $\geq 70 \%)$ & 3.34 (3.08 to 3.61$)$ & 5.09 (4.75 to 5.45$)$ & $1.22(1.18$ to 1.26$)$ & 0.72 (0.69 to 0.75$)$ & 0.70 (0.67 to 0.72$)$ \\
\hline No of observations & 12296 & 12696 & 12926 & 16220 & 16220 \\
\hline No of municipalities & 1537 & 1587 & 1622 & 1622 & 1622 \\
\hline
\end{tabular}

*Models adjusted for percentage of population below poverty line, per capita income (monthly), percentage of population having basic household appliances, percentage in households with inadequate sanitation, percentage illiteracy among $>15$ year olds, presence of local hospital beds, number of physicians per 1000 inhabitants, urbanisation rate, percentage highly educated among $>25$ year olds, and presence of tomography and ultrasonography in the municipality. †Rate during period 2000-09. 